\title{
Investigation of Some Antibacterial and Antioxidant Properties of Wild Cirsium vulgare from Turkey
}

\author{
Temine Sabudak ${ }^{1}$, H. Hulya Orak ${ }^{\star 2}$, Dumrul Gulen ${ }^{3}$, Merve Ozer ${ }^{1}$, Hilmican Caliskan', \\ Ilayda Bahrisefit ${ }^{1}$, Evren $\mathrm{Cabi}^{4}$
}

\begin{abstract}
${ }^{1}$ Department of Chemistry, Faculty of Science and Arts, Namik Kemal University, Tekirdag, TURKEY. 2Department of Food Technology, Vocational School of Technical Sciences, Namik Kemal Un., Tekirdag TURKEY. ${ }^{3}$ Department of Medical Microbiology School of Medicine, Namik Kemal University Tekirdag, TURKEY. ${ }^{4}$ Department of Biology,Faculty of Science and Arts, Namik Kemal University, Tekirdag, TURKEY.
\end{abstract}

\begin{abstract}
Background: Cirsium vulgare (Savi) Ten; belongs the Asteraceae family and has common uses in some countries folk medicine. Objective: In this study, the determination of some antioxidant and antimicrobial properties of $C$. vulgare which is wild-grown from Turkey is aimed. Methods: Crude extracts of plants were obtained by using n-hexane, diethyl ether, ethyl acetate and methanol as solvent. Total phenolic content (TPC) and DPPH (2,2-diphenyl 2,2-diphenyl-1 picrylhydrazyl picrylhydrazyl) scavenging activity were determined in extracts. The antibacterial activity was tested against Staphylococcus aureus (ATCC 43300), Escherichia coli (ATCC 35218), Bacillus subtilis (NRRL NRS-744) and Pseudomonas aeruginosa (ATCC 27853). Results: The TPC and DPPH activities of extracts revealed significant differences by following sequence $\mathrm{MeOH}>$ diethyl ether $>$ EtOAc $>$ n-hexane. The highest inhibition effect of $C$. vulgare was found on $P$. aeruginosa. Conclusion: Results presented that $C$. vulgare can be researched for future investigations for isolations of biologically active compounds, where some of their characteristics are expected to be contribute to the natural compounds in pharmaceutical industry.
\end{abstract}

Key words: Cirsium vulgare, Phenolic content, DPPH activity, Antibacterial activity, $P$. aeruginosa.

\section{INTRODUCTION}

Polyphenols are large group of natural compounds which possess wide spectrum of biological activity and many of them have been found in plant-based. The Asteraceae comprise one of the largest families of flowering plants with over 13.000 species in 1310 genera in worldwide. ${ }^{1}$ Some species that belonging to that family are studied for determination of their antioxidant activity.,3 Cirsium vulgare (Savi) Ten; belongs the Asteraceae which is represent one of the largest plant families. Cirsium species are very common and widespread plants in the traditional medicine of some countries, and these plants are used in the treatment of numerous diseases due to their diuretic, astringent, antiphlogistic or anxiolitic activities. ${ }^{4}$ C. vulgare, characterized also as injurious weed, with edible tap roots and stems - according to earlier literature data - contains flavonoids, sterols, aliphatic aldehydes and phenolic acids. ${ }^{5}$ The extracts from Cirsium species were also shown to possess antioxidant and antibacterial activity ${ }^{6}$

Antioxidants, exogenous and especially endogenous, are vital substances which possess the ability to protect the body from potent injuries caused by the free radicals. ${ }^{7}$ It was shown that the antioxidant activities found in plant natural products could provide protective effects via inhibiting DNA oxidative damage. ${ }^{8}$

Antibiotics are one of our most important weapons in fighting bacterial infections and have greatly benefited the health-related quality of human life since their introduction.
DOI: 10.5530/ijper.51.3s.48 Correspondence: H. Hulya Orak, Department of Food Technology, Vocational School of Technical

Sciences, Namik Kemal Un., Tekirdag TURKEY.

Phone no: +90 282 2505584; Fax no: +902822509928.

Email Id: horak@nku.edu.tr 
However, in recent years, many types of microorganisms with active infectious diseases have become resistant to antibiotics. Therefore, drugs derived from natural sources play a significant role in the prevention and treatments of human diseases. Actually, in many developing countries, traditional medicine is one of the primary healthcare systems. ${ }^{9}$ Among these compounds, polyphenols are large group of natural compounds and many of them have been found in plant-based.

C. vulgare is a species as wild-grown in Trakya region of Turkey. Along with the increasing interest in natural antimicrobials and antioxidants derived from plants, due to their use and benefit in food preservation and natural food additives, in this study, we aimed to determination of total phenolic content, antioxidant and antimicrobial activities of C. vulgare.

\section{MATERIAL \& METHODS}

\section{Plant Material}

C. vulgare which is wild plant species in Trakya region, was collected in June 2016. The specimens (NGBB 7229) were identified by Dr. Cabi at Namık Kemal University, Faculty of Science, Department of Biology.

\section{Extractions}

Crude extracts from plants obtained by using $n$-hexane, diethyl ether, ethylacetate (EtOAc), and methanol $(\mathrm{MeOH})$ extraction methods. Air dried samples were used for $n$-hexane, diethyl ether, EtOAc, MeOH solvent extractions. The extractions were repeated two times, supernatants were combined, and solvents were evaporated under vacuum using a rotary evaporator.

\section{Total Phenolic Content (TPC) assay}

The total phenolic content (TPC) in plant extracts was determined by a colorimetric method with Folin and Ciocalteu's phenol reagent. ${ }^{10}$ Total phenolic content was expressed as mg catechol equivalents (CAE).

\section{DPPH' scavenning activity}

The scavenging effect of free radicals was assayed by using DPPH (2,2-diphenyl 2,2-diphenyl-1 picrylhydrazyl picrylhydrazyl) method against DPPH radical and, monitored at $517 \mathrm{~nm}$ as described by Amarowicz et al 2002. ${ }^{11}$ The results were expressed as $\mathrm{IC}_{50}$ value $\left(\mathrm{IC}_{50}\right.$ is concentration needed for scavenging $50 \%$ of $\mathrm{DPPH}$ radical).

\section{Antibacterial activity}

The antibacterial activity was tested against four bacteria strains, which were Staphylococcus aureus (ATCC 43300),
Escherichia coli (ATCC 35218), Bacillus subtilis (NRRL NRS-744) and Pseudomonas aeruginosa (ATCC 27853). Bacterial suspensions in the logarithmic growth phase were diluted according to the McFarland 0.5 turbidity standard in Mueller-Hinton Broth and then $100 \mu \mathrm{l}$ from this suspension spread to agar plate surface plate. Plant extracts were solved in $1 \mathrm{ml}$ water and $100 \mu \mathrm{l}$ added to each well which were opened on the surface of the agar. Gram positive bacteria Penicillin $(10 \mathrm{IU} / \mathrm{ml})$ and for the other bacteria Gentamicin $(10 \mu \mathrm{g} / \mathrm{ml})$ are tested as control. Zone diameters are measured after $37^{\circ} \mathrm{C}$ incubation.

\section{RESULTS \& DISCUSSION}

\section{Antioxidant Properties of Cirsium vulgare}

Total phenolics extracted from samples were significantly affected by the extraction solvents, and methanol extracts had significantly higher phenolics than from the other extracts while n-hexane extracts was lowest as shown in Table 1. The DPPH scavenging activity of different solvents was concentration dependent similar to Jain ${ }^{12}$ and varied from 4.08-91.68 \% in extracts at different concentrations (Figure 1). $\mathrm{EC}_{50}$ values of DPPH activity in different solvents revealed significant differences similar to TPC content. This could be due to the differences in extractability of different solvents

\begin{tabular}{|c|c|c|}
\hline Extract & $\begin{array}{c}\text { Total Phenolic } \\
\text { content } \\
\text { ( } \mu \mathrm{g} \text { catechol Eq / mg } \\
\text { extract) }\end{array}$ & $\begin{array}{c}\text { EC }_{50} \\
\text { values of } D P P H \\
\text { activity }\end{array}$ \\
\hline $\mathrm{MeOH}$ & $61.21 \pm 0.37$ & $0.22 \mathrm{mg} /$ assay \\
\hline EtOAc & $12.13 \pm 0.06$ & $3.69 \mathrm{mg} / \mathrm{assay}$ \\
\hline Diethyl Ether & $13.75 \pm 0.08$ & $1.01 \mathrm{mg} /$ assay \\
\hline n-hexane & $0.008 \pm 0.01$ & $3.86 \mathrm{mg} /$ assay \\
\hline
\end{tabular}

* The antiradical activity was defined as the amount of antioxidant necessary to decrease the initial DPPH • concentration by $50 \%$ (Efficient Concentration = EC 50 ) -, was estimated based on the plot.

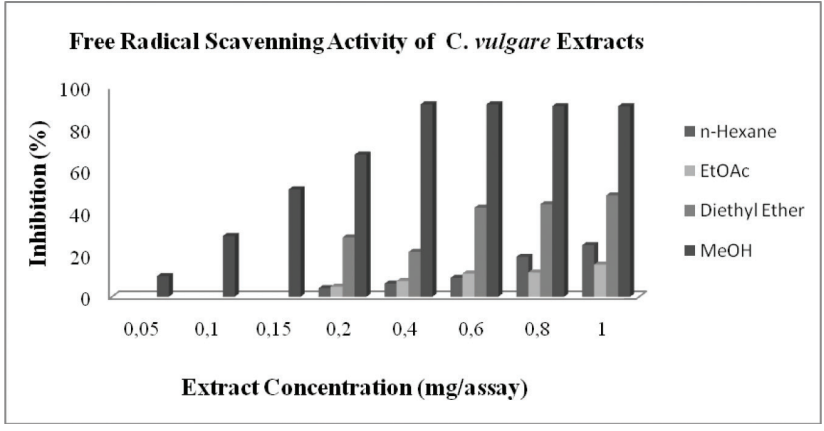

Figure 1: DPPH radical scavenging activity of $C$. vulgare extract. 
Table 2: Antibacterial activity of C. vulgare

\begin{tabular}{|c|c|c|c|}
\hline Bacteria & $\begin{array}{c}\text { Extract } \\
\text { zone }\end{array}$ & Penicilin & Gentamicin \\
\hline Staphylococcus aureus & $19 \mathrm{~mm}$ & $33 \mathrm{~mm}$ & - \\
\hline Bacillus subtilis & $21 \mathrm{~mm}$ & $30 \mathrm{~mm}$ & - \\
\hline Escherichia coli & $16 \mathrm{~mm}$ & - & $17 \mathrm{~mm}$ \\
\hline $\begin{array}{c}\text { Pseudomonas } \\
\text { aeruginosa }\end{array}$ & $22 \mathrm{~mm}$ & - & $15 \mathrm{~mm}$ \\
\hline
\end{tabular}

and it may be due to poor solubility of phenolics of this plant in hexane. This results in confirmed with the earlier determinations of Hossain. ${ }^{13}$ This may explain the solvent polarity and the use of different solvents of varying polarity may also lead to higher and lower mass transfer of different plant phenolics.

\section{Antibacterial Properties of Cirsium vulgare}

Methanol extracts used for determination antimicrobial activity and the zone diameters for the bacteria are shown on Table 2 . The highest antimicrobial activity of C. vulgare was found on $P$. aeruginosa among the bacteria strains which is $22 \mathrm{~mm}$ in diameter and higher than Gentamicin (15 mm zone diameter) as control. Some researchers ${ }^{14,15}$ determined that more effective antibacterial activity against $S$. aureus than E.coli, similarly.

\section{CONCLUSION}

Results presented that $C$. vulgare can be researched for future investigations for isolations of biologically active compounds, where some of their characteristics are expected to be contribute to the natural compounds in pharmaceutical industry. Additionally, because of their antimicrobial activity they can be used as topical preparation or by food preservation.

\section{ACKNOWLEDGEMENT}

This research was conducted with collaboration of different departments of Namik Kemal University.

\section{CONFLICT OF INTEREST}

The authors declare that they have no conflict of interest.

\section{ABBREVIATION USED}

$\mathrm{EC}_{50}$ : The amount of antioxidant necessary to inactivate $50 \%$ of initial DPPH; DPPH: 2,2-diphenyl-1picrylhydrazyl; TPC: Total phenolic content; EtOAc: Ethyl acetate; $\mathrm{MeOH}$ : Methanol; CAE: Catechol Equivalents.

\section{REFERENCES}

1. Heywood VH, Harborne JB, Turner BL. An overture to the Compositae. In: The Biology and Chemistry of the Compositae, Volume I, Heywood VH, Harborne JB, Turner BL (eds). Academic Press: London, New York: San Francisco; 1977. p.1-20.

2. Arora, D, Rani A, Sharma A. A review on Phytochemistry and ethnopharmacological aspects of genus Calendula. Pharm. Rev. 2013;7(14):179-87.

3. Nikolova, M. Screening of radical scavenging activity and polyphenol content of Bulgarian plant species. Pharmacognosy Res. 2011;3(4):256-9.

4. Kozyra M, Glowniak K. Phenolic acids in extracts obtained from the flowering herbs of Cirsium vulgare (Savi) Ten. growing in Poland. Acta Soc Bot Pol. 2013;82(4):325-9.

5. Jordon-Thaden IE, Louda SM. Chemistry of Cirsium and Carduus: A role in ecological risk assessment for biological control of weeds?, Biochem Syst Ecol. 2003;31(12):1353-96.

6. Nazaruk J, Czechowska SK, Markiewicz R, Borawska MH. Polyphenolic compounds and in vitro antimicrobial and antioxidant activity of aqueous extracts from leaves of some Cirsium species. Nat Prod Res. 2008;22(18):1583-8.

7. Percival M. Antioxidants. Clinical Nutrition Insights, 1998;10:1-4.

8. Abdel-lateif KS, Eldeab HA, Maghrabi IA. The Plant Natural Products: Their Antioxidants, Free Radical Scavengers, DNA Protection and Antimicrobial Activities. J Bioprocess Biotech. 2016;6:293.

9. Janovska D, Kubıkova K, Kokoska L. Screening for Antimicrobial Activity of Some Medicinal Plants Species of Traditional Chinese Medicine. Czech J. Food Sci. 2003;21(3):107-10.

10. Amarowicz R, Karamać M, Weidner S, Abe S, Shahidi F. Antioxidant activity of wheat caryopses and embryos extracts. J Food Lipids. 2002;9(3):201-10.

11. Amarowicz R, Karamać M, Kmita-Głażewska H, Troszyńska A, Kozłowska H, Antioxidant activity of phenolic fractions of everlasting pea, faba bean and broad bean. J. Food Lipids. 1996;3(3):199-211.

12. Jain S, Dwivedi J, Jain PK, Satpathy S, Patra A. Medicinal Plants for Treatment of Cancer. A Brief Review. Pharmacognosy Journal. 2016;8(2):87-102.

13. Hossain MA, Muhammad DS, Charles G, Muhammad I. In vitro total phenolics, flavonoids contents and antioxidant activity of essential oil, various organic extracts from the leaves of tropical medicinal plant Tetrastigma from Sabah. Asian Pac J Trop Med. 2011;4(9):717-21.

14. Agarwal A, Prajapati R, Raza SK, Thakur LK. GC-MS Analysis and Antibacterial Activity of Aerial Parts of Quisqualis indica Plant Extracts. Indian $\mathrm{J}$ of Pharmaceutical Education and Research. 2017;51(2):329-36.

15. Gurrapu S, Mamidala E. In vitro antibacterial activity of alkaloids isolated from leaves of Eclipta alba against human pathogenic bacteria. Pharmacog J. 2017;9(4):573-7. 


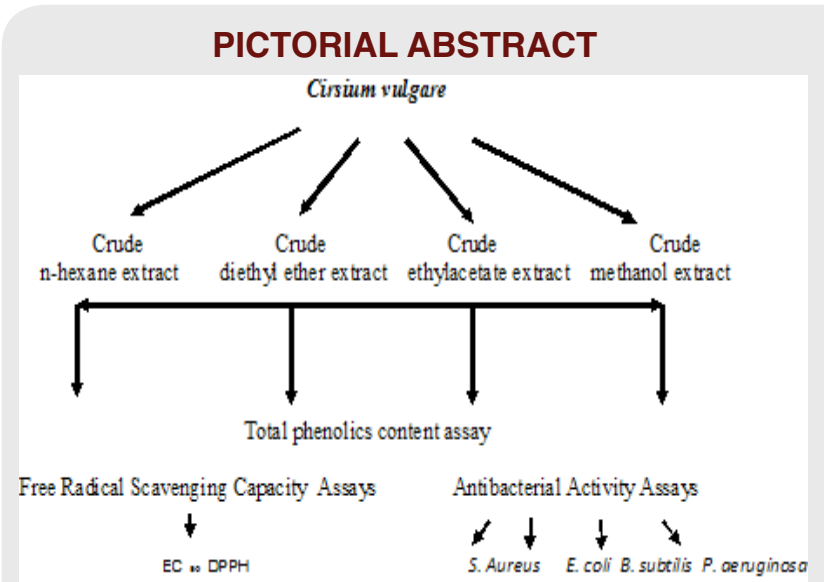

\section{ABOUT AUTHORS}

Temine Sabudak: Professor at Department of Chemistry, Faculty of Art and Sciences, University of Namik Kemal in Turkey. She is working on the chromatographic separation, purification and determination of chemical structures of organic compounds from natural products. Additionally her expert area is organic synthesis, spectroscopy phytochemistry.

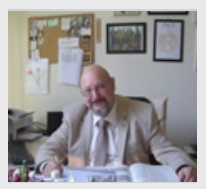

Dumrul GULEN: Associate Professor at Namık Kemal University School of Medicine Department of Medical Microbiology, Head of Tumor Biology \& Immunology Department Institute of Health Sciences, Editor of Journal of Hematology And Oncology Research (JHOR). Specific interests are Tumor immunotherapy, Tumor immunology, Investigation of antibacterial, antifungal, antitumoral effects of plant-derived substances

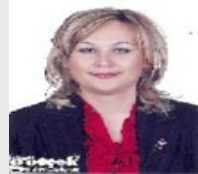

H. Hulya Orak: Associate Professor at Department of Food Tecnology, University of Namik Kemal in Turkey. She is interested in antioxidant activities of fruits, legumes, some plant materials and medical plants. Additionally her expert area is enzyme activities, drying and freezing technology of vegetables and fruits.

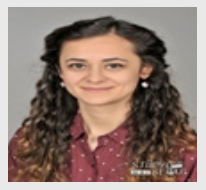

Merve Ozer: She is continuing her MSc at Department of Chemistry, Faculty of Science and Arts at Namik Kemal University and she is member of the Project of Tubitak (116Z450).

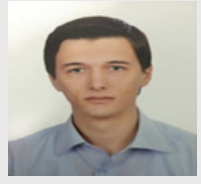

Hilmican Caliskan: He is continuing his MSc at Department of Chemistry, Faculty of Science and Arts at Namik Kemal University and he is member of the Project of Tubitak (116Z450).

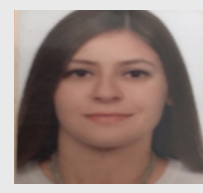

llayda Bahrisefit: She is continiue her MSc at Department of Chemistry, Faculty of Science and Arts at Namik Kemal University and she is member of the Project of Tubitak (116Z450). 


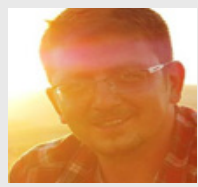

Evren Cabi: Associate Professor at Department of Biology, Namık Kemal University Faculty of Art and Sciences. His areas of research interest include 'Plant Systematics and Phylogeny', 'Ecology' and Conservational Biology'. He is author of over 100 peer-reviewed publications and 1 book chapter and 1 book. He collected the plant material from the natural flora of Turkey and identified them for this study.

Cite this article: Sabudak T, Orak HH, Gulen D, Ozer M, Caliskan H, Bahrisefit I, Cabi E. Investigation of Some Antibacterial and Antioxidant Properties of Wild Cirsium vulgare from Turkey. Indian J of Pharmaceutical Education and Research. 2017;51(3)Suppl:S363-67. 